\title{
Comparison of sporadic sodium layer characteristics observed at different time resolutions
}

\author{
Y. J. Liu ${ }^{1}$, B. R. Clemesha ${ }^{1}$, J. H. Wang ${ }^{2}$, and X. W. Cheng ${ }^{3}$ \\ ${ }^{1}$ Instituto Nacional de Pesquisas Espaciais Avenida dos Astronautas, 1758, 12227-010 São Jose dos Campos, Brazil \\ ${ }^{2}$ National Space Science Center, Chinese Academy of Sciences, Beijing, China \\ ${ }^{3}$ Wuhan Institute of Physics and Mathematics, Chinese Academy of Sciences, Wuhan, China
}

Correspondence to: Y. J. Liu (yingjie@laser.inpe.br)

Received: 11 January 2013 - Revised: 1 October 2013 - Accepted: 8 October 2013 - Published: 4 November 2013

\begin{abstract}
Sporadic sodium $\left(\mathrm{Na}_{\mathrm{s}}\right)$ layers, occurring in roughly the same height range as ionospheric sporadic-E layers, were first detected by lidar some $30 \mathrm{yr}$ ago. $\mathrm{Na}_{\mathrm{s}}$ layers have a typical thickness of a few hundred meters to a few $\mathrm{km}$, with peak atom concentrations several times that of the background layer. Despite a great deal of excellent work over the past decades, the source of $\mathrm{Na}_{\mathrm{S}}$ layers is still not altogether clear, partly as a result of our incomplete knowledge of $\mathrm{Na}_{\mathrm{s}}$ layer characteristics. In this paper we concentrate on some typical case studies chosen from the $\sim 127 \mathrm{~h}$ of sporadic sodium layer observations made at a time resolution of $1.5 \mathrm{~s}$ at Yanqing $\left(115.97^{\circ} \mathrm{E}, 40.47^{\circ} \mathrm{N}\right)$, Beijing, China. This is a much better time resolution than what has been employed in most earlier measurements. The results show that the $\mathrm{Na}_{\mathrm{s}}$ layer peak heights are dispersed at slightly different although adjacent heights. When averaged over several minutes, as has been the case with most earlier measurements, the height scatter results in an apparent layer thickness of a few $\mathrm{km}$. We conclude, therefore, that these dispersed peaks at different but adjacent heights constitute the 5 min $\mathrm{Na}_{\mathrm{S}}$ layer. Similar to the observations of sporadic-E-ion (Es) layers and meteor rate, we observe quasi-periodic fluctuations on a timescale on the order of several minutes in the peak height and the peak density of sporadic layers, which is a universal feature but concealed by the lower temporal resolution previously adopted. Spatially localized multiple scatterers and multiple thin layers with similar apparent movement in $\mathrm{Na}_{\mathrm{s}}$ layers are also found. We discuss the possible formation mechanism by the direct deposition of large swarms of micrometeoroids and demonstrate a typical example of meteor trails evolving into a $\mathrm{Na}_{\mathrm{s}}$ layer, which suggests that this mechanism might indeed occur.
\end{abstract}

Keywords. Atmospheric composition and structure (middle atmosphere - composition and chemistry)

\section{Introduction}

Every day, billions of microgram-sized extraterrestrial particles from sporadic meteor activity enter and ablate in the upper layers of the earth's atmosphere, which gives rise to the upper atmospheric ion and metallic layers observed by incoherent scatter radars (ISR) and lidars, respectively (Ceplecha et al., 1998; Dyrud et al., 2011; Janches et al., 2006). The Mesosphere and Lower Thermosphere (MLT) region shows various types of fine structure, like the polar mesospheric or noctilucent clouds (PMC/NLC), which are believed to consist of ice crystals with the nuclei of extraterrestrial meteoric dust (Clemesha, 2004; Janches et al., 2004), the sporadic-Eion (Es) layers believed to consist of metallic ions of meteoric origin, concentrated into a thin layer by the effect of wind-shear in the presence of the earth's magnetic field (Mathews, 1998; Whitehead, 1989), and the less well understood thin layers of meteoric metals known as sporadic neutral (Ns) layers. These were first observed in sodium by Clemesha et al. (1978), and have subsequently been detected in other metals such as iron, calcium, potassium and magnesium. The definition of what constitutes an Ns layer is necessarily somewhat subjective, but it generally involves a layer of metal atoms between a few hundred meters and a few kilometers thick, with a concentration equal to or greater than twice that of the background metal layer which in the case of sodium has a typical width of around $10 \mathrm{~km}$ (Clemesha et al., 1997). A number of different mechanisms have been 
suggested for the formation of these layers, including direct meteor deposition (Clemesha et al., 1978, 1988), the liberation of sodium from aerosol particles by auroral particle bombardment (von Zahn et al., 1987), redistribution of the background layer (Kirkwood and Collis, 1989), and sodium chemistry (von Zahn and Murad, 1990; Zhou et al., 1993; Zhou and Mathews, 1995), but none of these can account satisfactorily for all of the observed phenomena (Clemesha, 1995; Clemesha et al., 1999; Cox and Plane, 1998). The neutralization of wind-shear concentrated metallic ion-layers appears to be the most promising theory (Clemesha, 2004; Clemesha et al., 1999; Cox and Plane, 1998; Dou et al., 2010; Mathews et al., 1993). One of the reasons for believing that Ns layers are produced by neutralization of Es layers is the close, although not one-to-one, correlation of Ns occurrence with that of Es. Secondly, it provides an explanation for the most distinctive characteristic of Ns layers their small vertical extent. That is, ions are concentrated into a narrow layer by the action of electric and magnetic fields and wind shears and subsequently neutralized (Clemesha, 2004, 1995; Clemesha et al., 1999; Cox and Plane, 1998). Thirdly, a successful theory must explain the source strength required to produce a typical Sporadic sodium $\left(\mathrm{Na}_{\mathrm{s}}\right)$ layer (Cox and Plane, 1998). However, recent observations of $\mathrm{Na}_{\mathrm{s}}$ on a small timescale reveal that the instantaneous rate of change of $\mathrm{Na}$ atoms in a sporadic layer is often on the order of $100 \mathrm{~cm}^{-3} \mathrm{~s}^{-1}$ (Liu and Yi, 2009), which is too fast to be explained by the ion-molecule mechanism (Cox et al., 1993; Cox and Plane, 1998; Hansen and von Zahn, 1990). But as pointed out by Clemesha (1995) and Clemesha et al. (1997), the observed rapid growth rates could well represent not the formation of neutral metal atoms, but the advection of a cloud of neutrals of limited horizontal extent over the observing site. However, the altitude and abundance variations of Es layers and $\mathrm{Na}_{\mathrm{s}}$ layers have been found to be highly correlated (Beatty et al., 1989); the vertical and temporal structures of the $\mathrm{Na}$ and electron densities are remarkably similar and the $\mathrm{Na}$ and electron density variations in phase (Kane et al., 1993). Simultaneous incoherent scatter radar and sodium lidar measurements at Arecibo have shown that sodium abundance in the $90-110 \mathrm{~km}$ region frequently tracks the total electron content for the same height region (Mathews et al., 1993). Simultaneous and common-volume lidar observations show that the concurrent density/abundance increases or decreases often occurred in the correlated sporadic ionic and atomic layers (Gerding et al., 2001; Yi et al., 2013). The neutralization of wind-shear concentrated metallic ion-layers implies that the atomic and ionic/electronic layers show inverse variations in density/abundance. Furthermore, there is so far no clear-cut observational evidence that the Lorentz force in a sheared wind gathers the dispersed meteoric metal ions to form an Es layer with multiple metal ion species. The Lorentz force tends to separate those different species of metal ions because of their unlike masses (e.g., $\mathrm{Fe}^{+}, \mathrm{Ca}^{+}$, and $\mathrm{Na}^{+}$). In practice, while the wind shear tends to confine the plasma, the neutrals and ions would be separated vertically and horizontally from each other because of different driving forces on them. This is inconsistent with the facts that the correlated atomic and ionic/electronic layers were observed to occur in overlapping altitude ranges and follow almost the same track (Yi et al., 2013). Although the neutralization of wind-shear concentrated metallic ion-layers still provides the most plausible explanation for the sporadic neutral layers, there is still no indisputable answer to the question of how neutral metallic layers are formed. The study of the formation mechanism of $\mathrm{Na}_{\mathrm{s}}$ layers depends on understanding their essential characteristics, which relies on more extensive observational results.

Observations made with an $8 \mathrm{~s}$ time resolution (Liu and Yi, 2009) have shown that $\mathrm{Na}_{\mathrm{S}}$ layers typically consist of a series of density enhancement bursts and that $\mathrm{Na}_{\mathrm{s}}$ peak height often varies by several hundred meters on a timescale of $\sim 30 \mathrm{~s}$. Large-aperture sodium lidar with very high resolution reveals that the sodium layer can be highly structured with multiple layers varying in density and altitude on timescales ranging from minutes to hours (Pfrommer et al., 2009). Sodium lidar measurements with $5 \mathrm{~s}$ time resolution reveal the occurrence of dramatic sodium density increases as well as short-period wavelike structure in $\mathrm{Na}_{\mathrm{s}}$ layers with periods of several minutes (Tsuda et al., 2011). It is noteworthy that earlier observations were made at conventional time resolutions on the order of several minutes. Long integration periods will not only underestimate the apparent $\mathrm{Na}$ change rates, but also smooth out the fine structures of $\mathrm{Na}_{\mathrm{s}}$ layers, thus limiting our understanding of these $\mathrm{Na}_{\mathrm{s}}$ layers. This paper focuses on new experimental observations of $\mathrm{Na}_{\mathrm{s}}$ layers, and combined with existing knowledge of Es layers and meteoroids, evaluates the possible formation mechanism via direct deposition of large swarms of micrometeoroids proposed by Liu and Yi (2009) and Yi et al. (2008, 2013), based on observations at a time resolution of $1.5 \mathrm{~s}$ made at Yanqing, $\left(115.97^{\circ} \mathrm{E}\right.$, $40.47^{\circ} \mathrm{N}$ ) Beijing, China. These high resolution observations can be expected to reveal some previously unknown features in the $\mathrm{Na}_{\mathrm{s}}$ layer and to advance the study of the $\mathrm{Na}_{\mathrm{s}}$ formation mechanism.

\section{Instrumentation description}

A broadband sodium fluorescence lidar was set up at Yanqing $\left(115.97^{\circ} \mathrm{E}, 40.47^{\circ} \mathrm{N}\right)$ in November 2009 with the support of the Chinese Meridional Project. The transmitter consists of a tunable pulsed dye laser pumped by a frequency-doubled $\mathrm{Nd}$ :YAG laser with a pulse repetition rate of $30 \mathrm{~Hz}$. The dye laser employs a dual grating system controlled by a computer which enables a rapid selection of transmitted wavelength. The pulsed dye laser is fine-tuned to the D2 resonant absorption line of $\mathrm{Na}$ with the help of a $\mathrm{Na}$ vapor cell. The laser beam is expanded and transmitted into the atmosphere using a steering mirror. The backscattered photons are collected by 
Table 1. The main specifications of the Meridional Project Yanqing lidar.

\begin{tabular}{llc}
\hline Transmitter & Nd:YAG Laser & DYE Laser \\
\hline Wavelength & $532 \mathrm{~nm}$ & $589 \mathrm{~nm}$ \\
Linewidth & & $0.06 \mathrm{~cm}^{-1}$ \\
Pulse energy & $\sim 320 \mathrm{~mJ}$ & $\sim 60 \mathrm{~mJ}$ \\
Repetition rate & $30 \mathrm{~Hz}$ & $30 \mathrm{~Hz}$ \\
Pulse width & $\sim 8 \mathrm{~ns}$ & $\sim 8 \mathrm{~ns}$ \\
Beam divergence & $0.5 \mathrm{mrad}$ (before expansion) \\
External beam expander & \multicolumn{2}{c}{$\times 5$} \\
\hline Receiver & \multicolumn{2}{c}{$1 \mathrm{~m}$} \\
\hline Telescope diameter & \multicolumn{2}{c}{$1 \mathrm{mrad}$} \\
Field of view & \multicolumn{2}{c}{$5 \mathrm{~nm}$} \\
IF filter FWHM & \multicolumn{2}{c}{$55 \%$} \\
Peak transmission & \multicolumn{2}{c}{$640 \mathrm{~ns}$} \\
Bin width &
\end{tabular}

a receiving telescope with a 1-meter diameter primary mirror. A cooled photomultiplier tube is employed for the photon detection. The output pulses from the PMT are fed into a PC-based photon counting multi-channel scaler (MCS). The scaler counts the pulses in successive time bins. In order to study the characteristics of $\mathrm{Na}_{\mathrm{s}}$ on a small timescale, the photon counts from 25 laser shots are accumulated to yield a photon count profile. Due to the time needed for data transfer, the temporal resolution is $1.5 \mathrm{~s}$. The time bin is set to 640 nanoseconds, corresponding to a vertical resolution of $96 \mathrm{~m}$. The main specifications of the Yanqing lidar are listed in Table 1.

\section{Observational results}

The Yanqing sodium lidar was put into operation in November 2009. In order to study the fine structure of $\mathrm{Na}_{\mathrm{S}}$ layers on a small timescale, a temporal resolution of $1.5 \mathrm{~s}$ was adopted from 14 August 2010 to 27 September 2010. A total of $\sim 127 \mathrm{~h}$ of data from 14 nights of observations were collected during that period. The raw $1.5 \mathrm{~s}$ photon count profiles ( 25 pulses) were integrated to yield $5 \mathrm{~min}$ (5000 pulses) integrated profiles, then the density profiles of the "regular" sodium layer were derived using a standard inversion method (Gardner, 1989).

A $\mathrm{Na}_{\mathrm{s}}$ layer is defined as a narrow layer between a few hundred meters and a few kilometers thick, with concentration equal to or greater than twice that of the background sodium layer (Clemesha et al., 1999; Hansen and von Zahn, 1990; Yi et al., 2007). According to this definition, $24 \mathrm{Na}_{\mathrm{s}}$ layers were identified from this data set. Here we will focus on some case studies chosen from these $\mathrm{Na}_{\mathrm{s}}$ layers and show some previously unreported features.
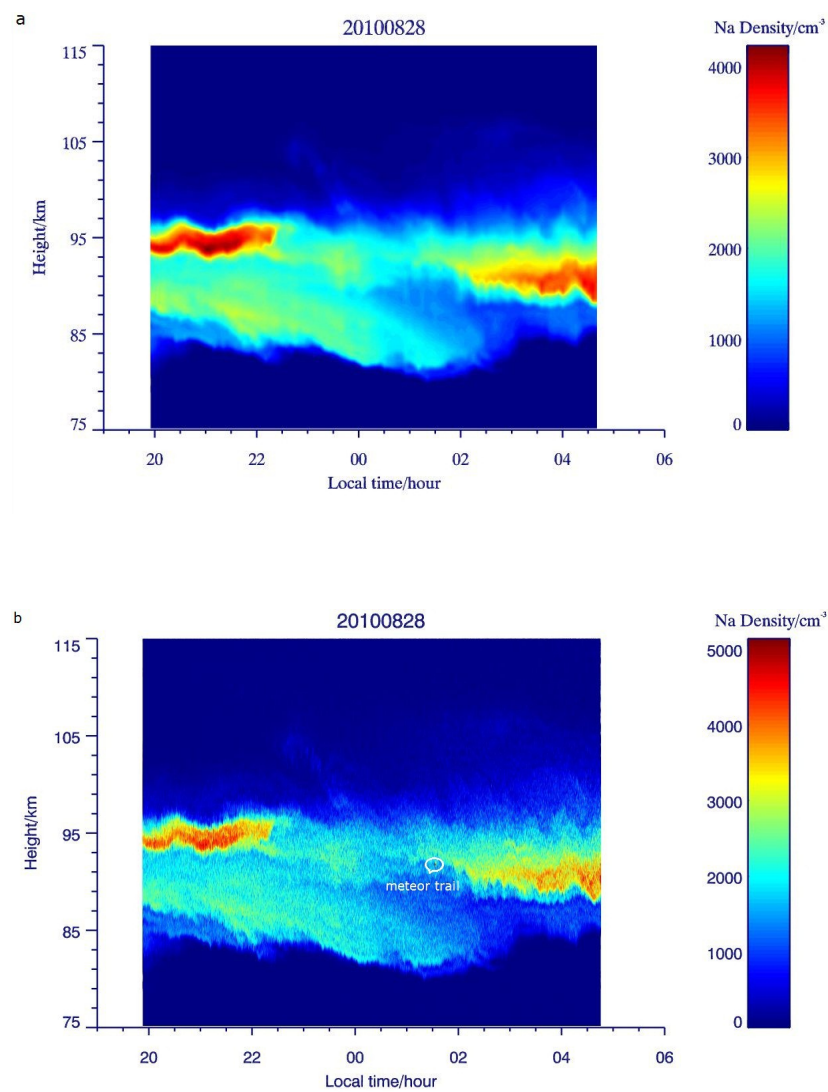

Fig. 1. Na density variations with time and height observed at different time resolutions on the night of 28 August 2010: (a) $5 \mathrm{~min}$; (b) $1.5 \mathrm{~s}$

\subsection{Case 1}

Figure 1a shows the observations on the night of $28 \mathrm{Au}-$ gust 2010 at the time resolution of $5 \mathrm{~min}$. There appeared two clear $\mathrm{Na}_{\mathrm{S}}$ layers on this night. One occurred at $\sim 93.79 \mathrm{~km}$ with a layer width of $\sim 3.74 \mathrm{~km}$, and a maximum peak density of $\sim 4227 \mathrm{~cm}^{-3}$, occurring at $\sim 21: 05 \mathrm{LT}$. This layer had already formed at startup and it disappeared at $\sim 22: 20 \mathrm{LT}$. The peak height exhibited an obvious fluctuation. The other layer occurred at $\sim 102.14 \mathrm{~km}$ with a width of $\sim 2.88 \mathrm{~km}$. Its maximum peak density was only $\sim 300 \mathrm{~cm}^{-3}$, occurring around $\sim 23: 15 \mathrm{LT}$, showing it to be a very weak event. It lasted $\sim 65 \mathrm{~min}$ and eventually merged into the background layer. Figure $1 \mathrm{~b}$ shows the same event at the full time resolution of $1.5 \mathrm{~s}$. Firstly, it can be seen that the peak density was higher than that seen in Fig. 1a, indicating that the $\mathrm{Na}_{\mathrm{s}}$ peak density was underestimated owing to the lower temporal resolution adopted, as pointed out in Liu and Yi (2009). Secondly, the density variations are less smooth than in Fig. 1a, but their structure was displayed more obviously. It is interesting to note that the higher resolution makes it possible to observe a meteor trail which occurred at $\sim 01: 33 \mathrm{LT}$ around $\sim 91.78 \mathrm{~km}$ with a peak density of $\sim 5137 \mathrm{~cm}^{-3}$, which, in 


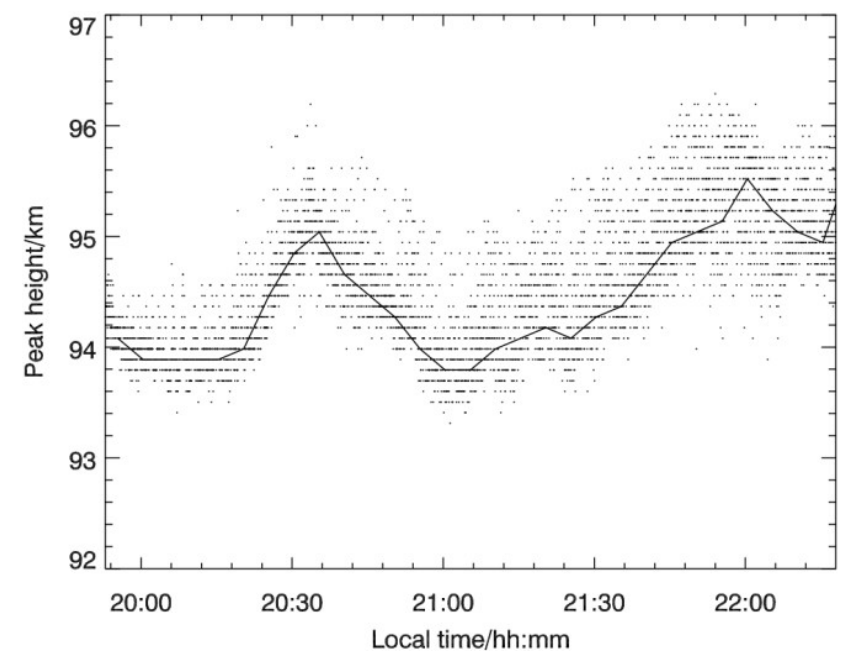

Fig. 2. Peak height variations of $\mathrm{Na}_{\mathrm{s}}$ layer shown in Fig. 1 observed at different time resolutions. The dots show the data with $1.5 \mathrm{~s}$ resolution and the solid line shows the same data with 5 min resolution.

Fig. 1a, was smoothed out owing to the lower time resolution adopted. In Fig. 1b multiple peaks can be discerned in the $\mathrm{Na}_{\mathrm{s}}$ layers which appear as single layers in Fig. 1a.

In order to illustrate more clearly the scatter in the peak heights of the $\mathrm{Na}_{\mathrm{s}}$ layers we have plotted these in Fig. 2. In this figure the dots indicate the peak heights observed at the time resolution of $1.5 \mathrm{~s}$, and the solid line represents the same data observed at the $5 \mathrm{~min}$ time resolution. As can be clearly seen, the $1.5 \mathrm{~s}$ samples are spread over a comparatively wide range of heights. Their spatial distribution reflects the form of the $\mathrm{Na}_{\mathrm{s}}$ layers shown in Fig. 1a, observed at the time resolution of $5 \mathrm{~min}$. Numerical simulations show that the spread cannot be explained as photon noise in the received signal (see Sect. 4.1). Note that the $5 \mathrm{~min}$ data also showed longer term height fluctuations which could obviously not be the result of photon noise. Consequently, we conjecture that the form of the $\mathrm{Na}_{\mathrm{s}}$ layers observed at the conventional time resolution (usually several minutes) arises from the smoothing effect of multiple peaks dispersed at adjacent heights. This is also consistent with the observation that the FWHM of $\mathrm{Na}_{\mathrm{s}}$ increased when multiple peaks appeared (Tsuda et al., 2011). The Lomb-Scargle spectral analysis shows that there existed quasi-periodic fluctuations in the peak height with the period of $\sim 16, \sim 20, \sim 36 \mathrm{~min}$. Furthermore, the quasiperiodic fluctuations with the period of $\sim 12, \sim 14, \sim 17$, $\sim 20, \sim 26$ and $\sim 36$ min also existed in the peak density.

\subsection{Case 2}

Figure 3 shows the result of observations made on the night of 27 August 2010. Figure 3a is the result observed at the 5 min time resolution, and Fig. $3 \mathrm{~b}$ that observed at the $1.5 \mathrm{~s}$ time resolution. During this period of time two $\mathrm{Na}_{\mathrm{s}}$ layers appeared. One occurred at the height of $\sim 101.09 \mathrm{~km}$ at
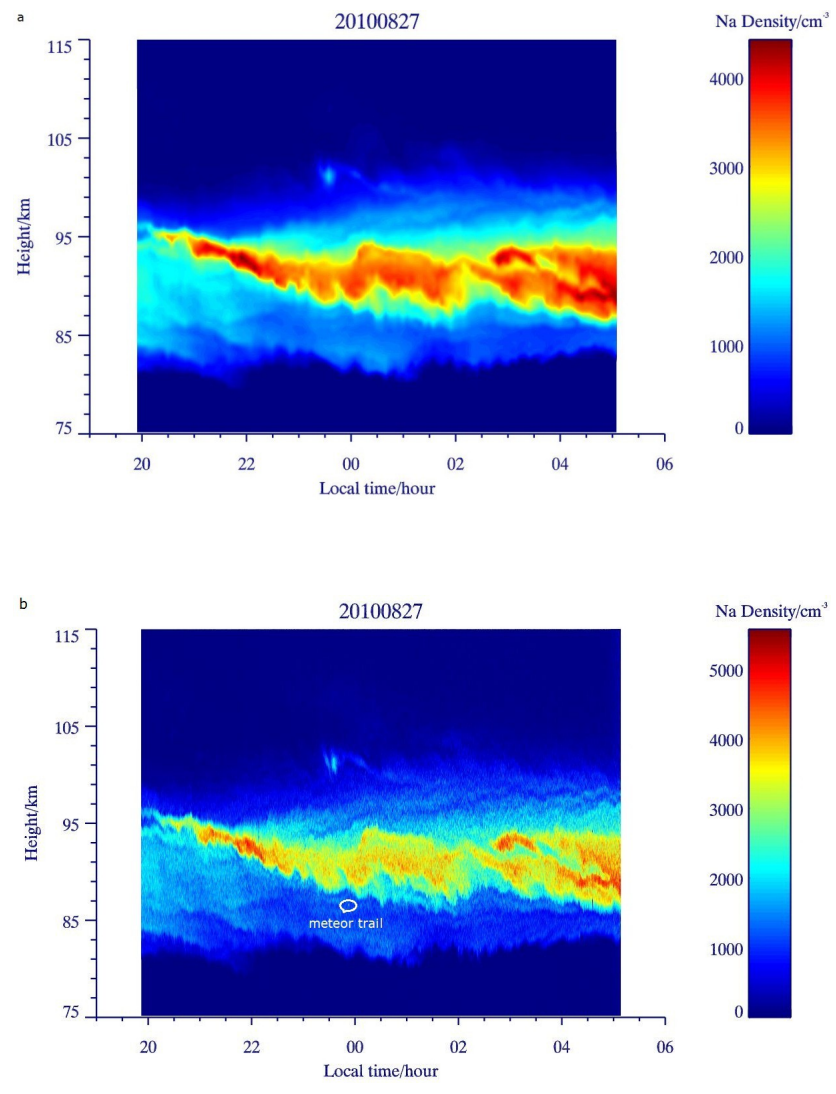

Fig. 3. Na density variations with time and height observed at different time resolutions on the night of 27 August 2010: (a) $5 \mathrm{~min}$; (b) $1.5 \mathrm{~s}$.

$\sim 23: 34$ LT with a maximum peak density of $\sim 1545 \mathrm{~cm}^{-3}$. This layer lasted about $70 \mathrm{~min}$ and subsequently faded into the background layer. The other layer began at $\sim 20: 15 \mathrm{LT}$, and reached a maximum peak density of $\sim 4425 \mathrm{~cm}^{-3}$ at a height of $\sim 92.93 \mathrm{~km}$ at $\sim 21: 54 \mathrm{LT}$, vanishing at $\sim 02: 15 \mathrm{LT}$, after lasting a total of $6 \mathrm{~h}$. Throughout the existence of this $\mathrm{Na}_{\mathrm{S}}$ layer, its width continuously increased. The peak height descended as a whole for the first $4 \mathrm{~h}$ and then increased suddenly at $\sim$ 00:00 LT, and about $30 \mathrm{~min}$ later it fell again until it disappeared at around 02:00 LT. Figure $3 \mathrm{~b}$ shows the result observed at the $1.5 \mathrm{~s}$ time resolution. Compared to Fig. 3a, the maximum peak density was higher as expected. More importantly, the structure of the sodium layer appeared more clearly. A meteor trail that occurred around $\sim 86.59 \mathrm{~km}$ at $\sim 23: 53 \mathrm{LT}$, visible in the high resolution data, is not visible in Fig. 3a, because of the smoothing effect of the $5 \mathrm{~min}$ time resolution. Furthermore, that the $\mathrm{Na}_{\mathrm{s}}$ layers occurred at discrete heights is more obvious, as in the case of those visible around $\sim 23: 00$ LT. Most typically, some peaks were almost completely separated from others around $\sim 93.5 \mathrm{~km}$ during the period $\sim 00: 10$ to $\sim 01: 30 \mathrm{LT}$, and thus appeared as very thin layers, which in Fig. $3 \mathrm{a}$ are merged with the other peaks making the sporadic layer appear continuous. Figure 4 


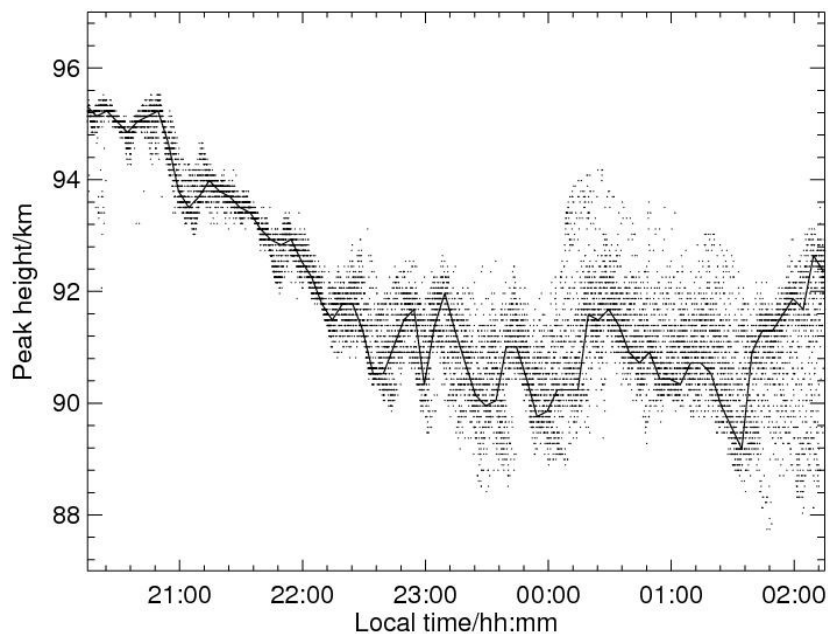

Fig. 4. Peak height variations of $\mathrm{Na}_{\mathrm{s}}$ layer shown in Fig. 3 observed at different time resolutions, the dots representing the $1.5 \mathrm{~s}$ resolution, and the solid line corresponding to $5 \mathrm{~min}$ resolution.

shows the distribution of these peak heights. The solid line represents the $5 \mathrm{~min}$ peak height, and the dots indicate the $1.5 \mathrm{~s}$ peak heights. As is seen clearly, the $1.5 \mathrm{~s}$ peak heights are scattered around the 5 min peak heights. The range became increasingly wide, as the $\mathrm{Na}_{\mathrm{s}}$ layer width increased. At $\sim 00: 00 \mathrm{LT}$, these peaks seemed to move to a new height as a whole, an event which corresponded to the rising peak height of the 5 min data. Also visible in Fig. 4 is an oscillation in the $5 \mathrm{~min}$ peak height with an amplitude of around $1 \mathrm{~km}$ and a period of about $30 \mathrm{~min}$. Similar to Case 1, there existed quasi-periodic fluctuations in the peak height with periods of $\sim 11-14, \sim 18, \sim 24, \sim 33$ min. Similar quasi-periodic oscillations also appeared in the peak density, with periods of $\sim 8-16, \sim 21, \sim 25, \sim 30 \mathrm{~min}$. The existence of these oscillations implies that these dispersed peak heights in $\mathrm{Na}_{\mathrm{s}}$ layers are not caused by photon count noise.

\subsection{Case 3}

Among the $\mathrm{Na}_{\mathrm{s}}$ layers observed, that with the most complex structure is shown in Fig. 5. Because it began to develop shortly before dawn, we were unable to observe its decay, but the formation process was demonstrated clearly. The sporadic layer appeared around $\sim 91.10 \mathrm{~km}$ with a maximum peak density of $\sim 4158 \mathrm{~cm}^{-3}$ occurring at $\sim 05: 03 \mathrm{LT}$ on 26 August 2010, and a layer width of $\sim 6.91 \mathrm{~km}$ (deduced from the observations we could obtain before sunrise). The sporadic layer consisted of several branches, one moving downward and the other upward, merging into a single layer at around 04:45 LT. A careful examination shows that there appeared a third layer on the topside which lasted for an extremely short time and then merged with the other two branches. We also noted that this merged $\mathrm{Na}_{\mathrm{s}}$ layer was the thickest of these $\mathrm{Na}_{\mathrm{s}}$ layers observed. Figure $5 \mathrm{~b}$ shows the
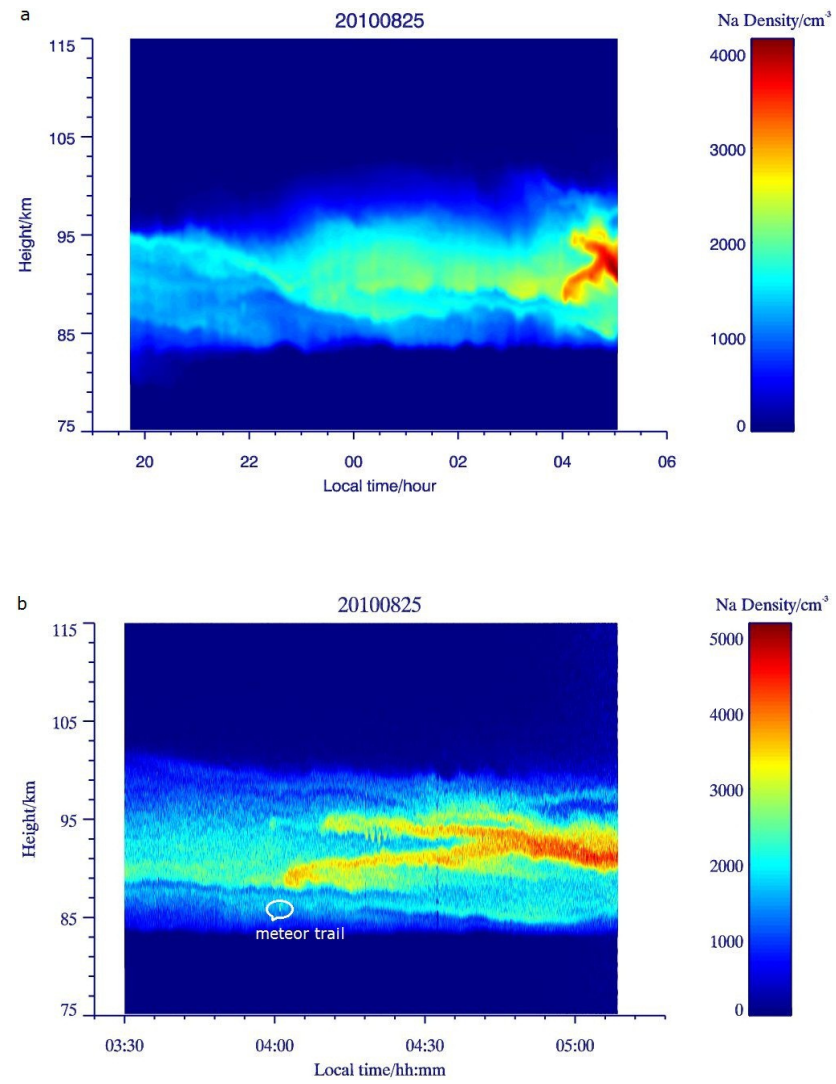

Fig. 5. Na density variations with time and height observed at different time resolutions on the night of 25 August 2010: (a) $5 \mathrm{~min}$; (b) $1.5 \mathrm{~s}$.

observations on an expanded timescale at the temporal resolution of $1.5 \mathrm{~s}$. In order to see the $\mathrm{Na}_{\mathrm{s}}$ evolution clearly, only a short stretch of data was extracted to be shown here. It is evident that lots of details of the sodium layer structure were manifested, like the meteor trail with a peak density of $\sim 3154 \mathrm{~cm}^{-3}$ occurring around $\sim 86.02 \mathrm{~km}$ at $\sim 04: 01 \mathrm{LT}$, just before the lower branch of the $\mathrm{Na}_{\mathrm{s}}$ layer began to form. Even though it was only one branch of this $\mathrm{Na}_{\mathrm{s}}$ layer, it behaved in a similar way to the whole $\mathrm{Na}_{\mathrm{S}}$ event, i.e., its peak was dispersed over a range of heights. Most prominently, it spread downward at $\sim 04: 06 \mathrm{LT}$ as well as at $\sim 04: 35 \mathrm{LT}$, which made it appear widened in Fig. 5a. The discrete nature of the layer manifested itself more remarkably in the upper branch of the $\mathrm{Na}_{\mathrm{s}}$ layer, which involved 4 isolated sporadic centers around $\sim 93 \mathrm{~km}$ from $\sim 04: 17 \mathrm{LT}$ to $\sim 04: 23 \mathrm{LT}$. At $\sim$ 04:30 LT, the third branch appeared, almost detached from the other two in height, and blended into them at $\sim 04: 52 \mathrm{LT}$. They then moved downward as a single entity and widened a little until shutdown. In fact, such discrete scattering regions can also be discerned from Fig. 1c of Pfrommer et al. (2009), which indicates that multiple discrete scattering regions might be an inherent phenomenon of $\mathrm{Na}_{\mathrm{s}}$ layers, only concealed by the lower time resolution previously adopted. 


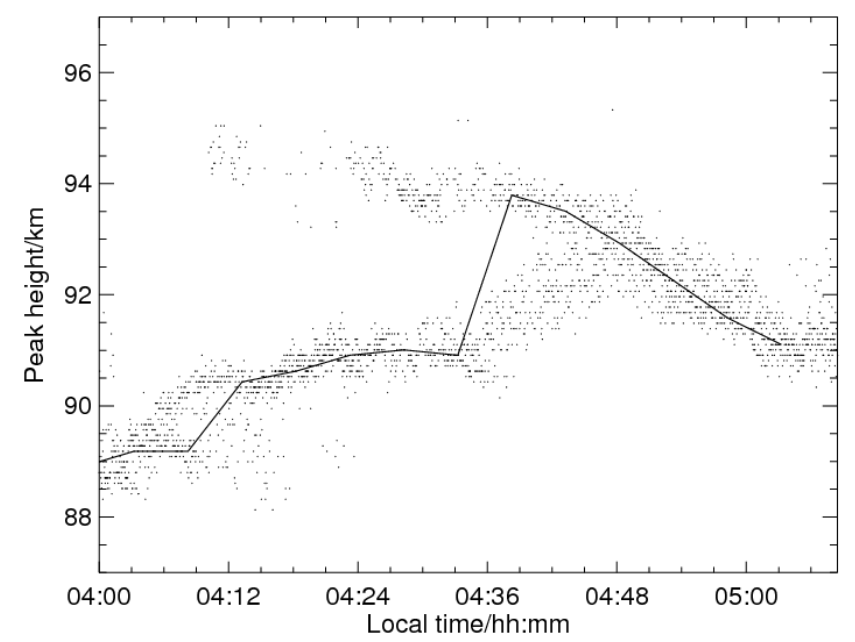

Fig. 6. Variations in the peak height of the $\mathrm{Na}_{\mathrm{S}}$ layer corresponding to Fig. 5 observed at different time resolutions. Dots show the $1.5 \mathrm{~s}$ time resolution data, and the solid line represents the $5 \mathrm{~min}$ observations.

Interestingly, a number of discrete, localized, patchy scatterers have also been seen in sporadic E layers (Hysell et al., 2002, 2004), and multiple scattering bodies were found in the meteor observations, too (Mathews et al., 2010). Besides, multiple thin layers also existed, only too weak to be noticed easily, such as the one around $97 \mathrm{~km}$ from $\sim 04: 50 \mathrm{LT}$ until shutdown. Such thin layers were observed frequently by high time resolution lidar (Pfrommer et al., 2009). Figure 6 shows the detailed evolution of these peaks. As expected, the envelope of the $1.5 \mathrm{~s}$ peak height distribution accurately reflects the shape of the $\mathrm{Na}_{\mathrm{s}}$ layer observed at the time resolution of 5 min.

\section{Discussion}

\subsection{Error analysis}

With the decrease of the integration period, and consequently the photon counts, the Poisson error can increase substantially, which is why most measurements made in the past have used an integration time of several minutes. Consequently, the reliability of the $1.5 \mathrm{~s}$ observations needs to be confirmed. A numerical simulation was used to estimate the measurement error of the $1.5 \mathrm{~s}$ peak height. The signal error in a photon counting lidar receiver arises from shot noise in the individual channel counts. This error is easily estimated by assuming a Poisson distribution for the photon counts. The propagation of this error to the sodium height distribution can then be estimated by means of a numerical simulation. Supposing $\mathrm{Na}_{\mathrm{s}}$ layers have the form of $A(x)=A_{0} \exp \left[-\left(x-x_{0}\right)^{2} / \Delta^{2}\right]$, where $A_{0}$ represents the peak photon count, $x_{0}$ the peak height, and $\Delta$ corresponding to the width where the photon count decreases to $1 /$ e times the peak photon count. $A_{0}, x_{0}$ and $\Delta$ can be obtained from the observations, so the above function is determined. To simulate the effects of shot noise, we superimpose a noise with the form of $\sqrt{A(x)}(2 n(x, t)-1)$ on the signal, where $n(x, t)$ is a uniformly distributed random number in the range $(0,1.0)$. Each time the noise changes, we get a new peak height. This procedure was repeated 10000 times for a range of typical data values and the standard deviation of the resulting peak heights was taken as the measurement error in the $1.5 \mathrm{~s}$ peak height due to photon count noise. Even for a $\mathrm{Na}_{\mathrm{S}}$ layer with a full width of $6 \mathrm{~km}$ at $1 / e$ times the maximum, the resulting height measurement error was only $\sim 300 \mathrm{~m}$, far less than the calculated mean fluctuation amplitude of $\sim 3.52 \mathrm{~km}$ in the $1.5 \mathrm{~s}$ peak height, so the measured $1.5 \mathrm{~s}$ peak height fluctuation must reflect a real geophysical phenomenon rather than merely the photon noise. In order to justify this further, the most typical $1.5 \mathrm{~s}$ photon count profile for each $\mathrm{Na}_{\mathrm{s}}$ layer is shown in Fig. 7. The blue diamond represents where the $\mathrm{Na}_{\mathrm{s}}$ layer appeared, and the blue dashed line indicates the half maximum of the peak photon count. For the majority of cases, the photon count returned from each peak, marked with the blue diamond, was far higher than its neighbors, and the photon counts in the FWHM neighborhood were also significantly higher than those around them. Although the peak height is not the best estimator in such a high noise environment, it is certain to fall within the FWHM height range, or more exactly speaking, to fall within these very thin layers. On this basis we can conclude that the peak height measurement error is far less than the $1.5 \mathrm{~s}$ peak height fluctuation amplitude. In some cases, like the $\mathrm{Na}_{\mathrm{s}}$ layers that occurred at 23:32:22 LT on 14 August, 23:19:03 LT on 28 August, 21:51:37 and 23:23:04 LT on 23 September, the layers are not so strong, and they correspond to some weak $\mathrm{Na}_{\mathrm{s}}$ events that occurred above $100 \mathrm{~km}$. Therefore, these dispersed peaks at different but adjacent heights must constitute the $5 \mathrm{~min} \mathrm{Na}_{\mathrm{s}}$ layer.

\subsection{The quasi-periodic oscillation phenomenon in $\mathrm{Na}_{\mathrm{s}}$ layers}

As described above, quasi-periodic oscillations in peak heights of $\mathrm{Na}_{\mathrm{s}}$ layers were frequently observed. Here we will show a very unusual $\mathrm{Na}_{\mathrm{s}}$ layer seen during this observation, which consisted of two thin layers with similar oscillation, as shown in Fig. 8. It was observed on 15 August 2010. During this night, the sodium layer was particularly active and the shape of the layer appeared chaotic, unlike the observations on other nights. The whole height range seemed to be disturbed, especially from dusk till midnight. Here we will focus on the observations between 22:30 and 01:30 LT. About 22:48 LT, a very thin layer with width less than $1 \mathrm{~km}$ appeared around $96.6 \mathrm{~km}$. For convenience, we will call it the main $\mathrm{Na}_{\mathrm{s}}$ layer here. At $\sim 23: 03 \mathrm{LT}$, it reached a maximum of $\sim 3085 \mathrm{~cm}^{-3}$ at $95.8 \mathrm{~km}$. It is noteworthy that at $\sim 23: 36$ LT there appeared distinctly another thin layer at 

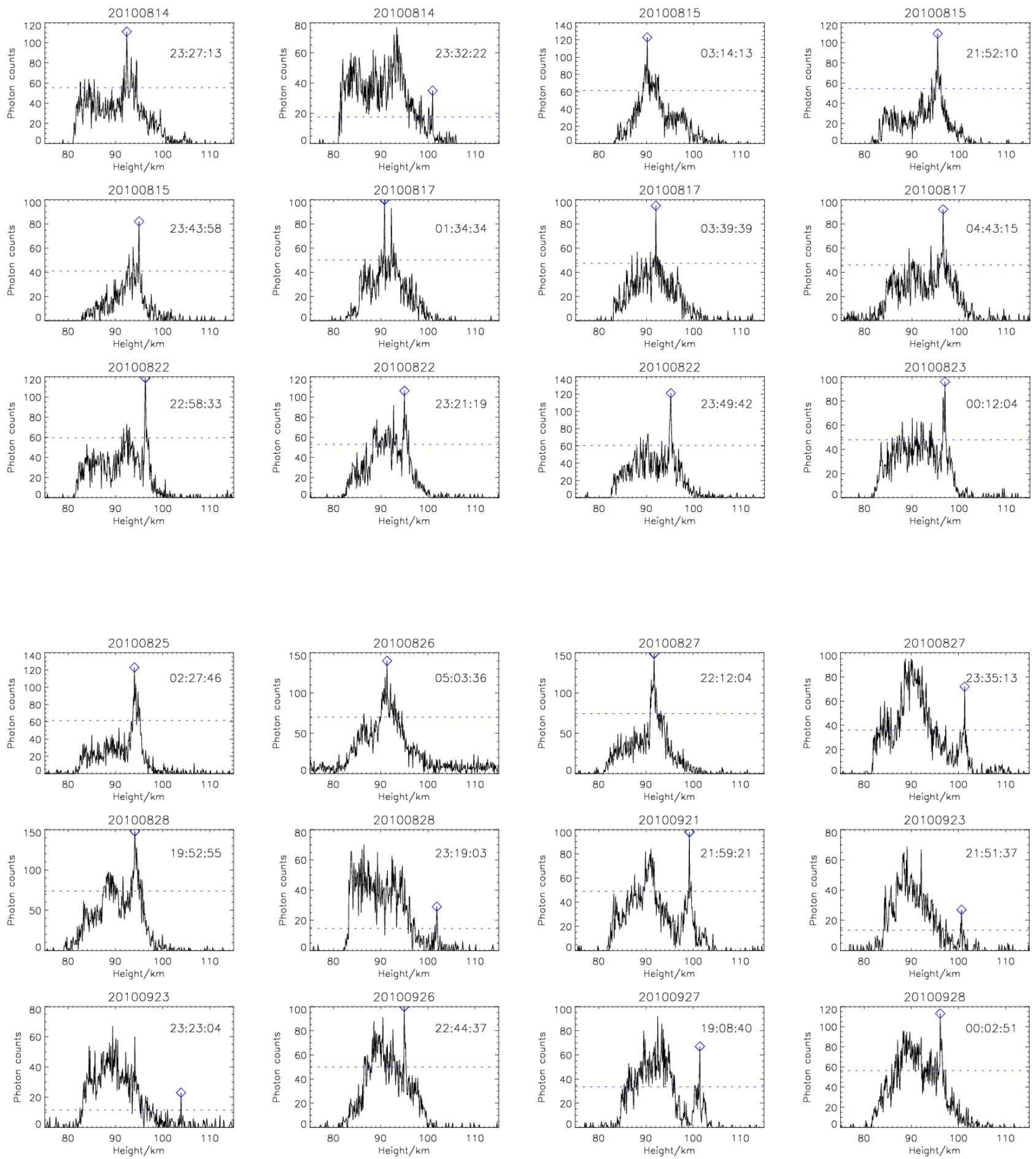

Fig. 7. The most typical $1.5 \mathrm{~s}$ photon count profiles during each $\mathrm{Na}_{\mathrm{s}}$ layer observed to show the reliability of observations. The blue diamond represents where the $\mathrm{Na}_{\mathrm{s}}$ layer appeared, and the blue dashed line indicates the half maximum of the peak photon count.

about $\sim 1 \mathrm{~km}$ below the main $\mathrm{Na}_{\mathrm{s}}$ layer, following almost the same trajectory until $\sim 00: 05$ LT when the lower layer disappeared. Their trajectories are highly correlated with a correlation coefficient of 0.89 , which indicates that their height variations were not caused by noise and that they must reflect a real geophysical process. The main layer continued and at $\sim 00: 30 \mathrm{LT}$, it appeared to become diffuse on the bottom side but the upper envelope had a clear boundary with the background and still exhibited an obvious quasi-periodic fluctuation until it merged with the background and became 


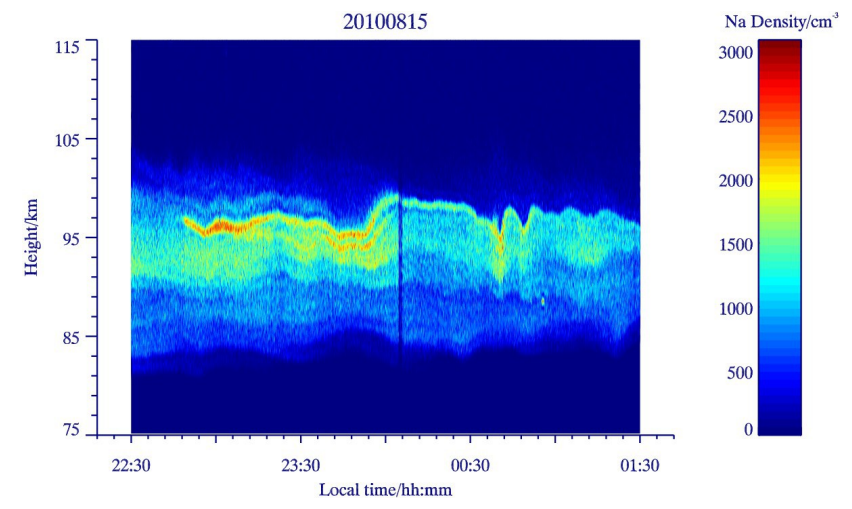

Fig. 8. Na density variations with time and height observed at the time resolution of $1.5 \mathrm{~s}$ on the night of 15 August 2010 to show the concurrent multiple thin layers with similar movement.

indistinguishable, which indicates that it was not a diffusion process that dominated its disappearance, otherwise it would diffuse both upward and downward. In fact, there also appeared a faint layer at about $1 \mathrm{~km}$ above the main $\mathrm{Na}_{\mathrm{S}}$ layer, following almost the same trajectory while the main $\mathrm{Na}_{\mathrm{s}}$ layer began to form. It disappeared at about $\sim 23: 36 \mathrm{LT}$. At about $\sim 00: 40 \mathrm{LT}$, there also appeared a third layer below the main $\mathrm{Na}_{\mathrm{s}}$ layer, dimly discernible because of its extremely short duration, when the peak density reached a local maximum. Such multiple layers were also observed in Case 2 between $\sim$ 20:00 and 21:00 LT, only too weak to be discerned easily. Note, at $\sim 00: 56 \mathrm{LT}$ a meteor trail appeared at $\sim 88.5 \mathrm{~km}$ with the peak density of $\sim 2573 \mathrm{~cm}^{-3}$.

During the whole process, the peak height of this $\mathrm{Na}_{\mathrm{s}}$ layer exhibited an obvious quasi-periodic fluctuation with the periods of $\sim 7.7, \sim 9, \sim 11$, and $\sim 15 \mathrm{~min}$, as indicated by the vertical dotted lines in Fig. 9. This is consistent with the observations of Mathews et al. (1993), Pfrommer et al. (2009) and Tsuda et al. (2011). The peak density also varied in a similar way. Note some significant spectral components coincided exactly both in the peak height and in the peak density, like the fluctuations with the periods of $\sim 11$ and $\sim 15 \mathrm{~min}$, which implies that these thin layers must be dominated by some physical process rather than being the result of photon count noise. Besides, it seems that the peak height reached a minimum as the peak density attained maximum as a whole, like those around $\sim 23: 03, \sim 23: 48$ and $\sim 00: 40$ LT. The periods on the order of several minutes in the peak height and in the peak density are not consistent with the intrinsic periods of gravity waves (Tsuda et al., 2011). What is more, the fact that the disturbed height range, corresponding to the $\mathrm{Na}_{\mathrm{s}}$ layer width, is far less than the vertical wavelength expected from gravity waves also indicates that the oscillation was not caused by a gravity wave. That the layer width did not broaden with time uniformly as shown in Fig. 8 indicates that the subsequent layer is not the result of diffusion of its

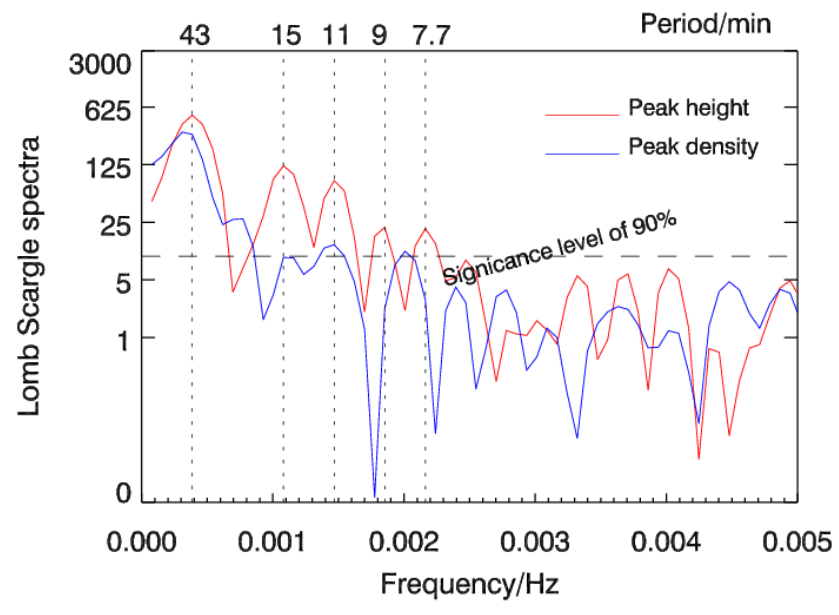

Fig. 9. The normalized Lomb-Scargle spectra of the peak height (red) and the peak density (blue) of the main $\mathrm{Na}_{\mathrm{s}}$ layer shown in Fig. 8. The vertical dotted lines represent some significant spectral components in the peak height, and the horizontal dashed lines indicate the significance level of $90 \%$.

previous state. We might speculate that this rapid oscillation could be related to the ripples seen on airglow images.

Table 2 lists the peak height variation of all these $24 \mathrm{Na}_{\mathrm{s}}$ events, including the peak occurrence time, the corresponding peak height, the layer width and the duration, as well as the dominant quasi-periodic oscillations. It can be seen that each $\mathrm{Na}_{\mathrm{s}}$ layer exhibited obvious quasi-periodic oscillations, with the oscillation period varying from several minutes to tens of minutes. Depending on the time span and the strength of each $\mathrm{Na}_{\mathrm{S}}$ layer, their respective dominant quasi-periodic oscillations differ to some extent, but oscillating components with period less than $15 \mathrm{~min}$ were frequently observed among them. The regular sodium layer was also analyzed, and such short-period oscillating components were not found in the peak height, which indicates that it is a characteristic of sporadic sodium layers.

Interestingly, sporadic E layers have also been observed to behave similarly, including quasi-periodic echoes with the period of several minutes and the multiple simultaneous layers (Hysell et al., 2004; Hysell and Burcham, 1999; Mathews et al., 1993). It has been believed that there is a strong link between the formation of $\mathrm{Na}_{\mathrm{s}}$ layers and Es layers, because of their frequently simultaneous occurrence and similar structure (Beatty et al., 1989; Gardner et al., 1993; Kane et al., 1991, 1993; Mathews et al., 1993; von Zahn et al., 1989; von Zahn and Hansen, 1988). The present observations confirm the strong link between them. In this paper we will not attempt a comprehensive explanation, but will discuss a possible mechanism of direct deposition of large swarms of micrometeoroids proposed by Liu and Yi (2009) and Yi et al. $(2008,2013)$. With regard to the relationship between $\mathrm{Na}_{\mathrm{S}}$ layers and Es layers, there are two suggestions. The first is that both ionized Es layers and neutral $\mathrm{Na}_{\mathrm{s}}$ layers are formed 
Table 2. The peak height variation of these $24 \mathrm{Na}_{\mathrm{s}}$ layer events.

\begin{tabular}{|c|c|c|c|c|c|c|c|c|c|}
\hline \multirow{2}{*}{$\begin{array}{l}\text { Observation } \\
\text { night } \\
\text { year } 2010\end{array}$} & \multirow{2}{*}{$\begin{array}{l}\text { Peak } \\
\text { time } \\
(\mathrm{LST})\end{array}$} & \multirow{2}{*}{$\begin{array}{r}\text { Peak } \\
\text { height } \\
(\mathrm{km})\end{array}$} & \multirow{2}{*}{$\begin{array}{r}\text { Peak } \\
\text { density } \\
\left(\mathrm{cm}^{-3}\right)\end{array}$} & $\begin{array}{l}\text { Layer } \\
\text { width } \\
(\mathrm{km})\end{array}$ & $\begin{array}{l}\text { Duration } \\
\text { (min) }\end{array}$ & \multicolumn{4}{|c|}{$\begin{array}{l}\text { Quasi-period oscillations } \\
\text { in } 1.5 \mathrm{~s} \text { peak height }(\mathrm{min})\end{array}$} \\
\hline & & & & & & & & & \\
\hline 14 Aug & $23: 22$ & 93.41 & 2643 & 5.18 & 135 & & 31 & 21 & 15 \\
\hline 14 Aug & $23: 27$ & 104.93 & 235 & 3.36 & 180 & & & 53 & 35 \\
\hline 15 Aug & $03: 32$ & 89.38 & 3331 & 6.62 & $\mathrm{NA}^{*}$ & & 33 & 23 & 13 \\
\hline 15 Aug & $21: 54$ & 95.90 & 3051 & 3.26 & 25 & & & & 11 \\
\hline $15 \mathrm{Aug}$ & $23: 04$ & 96.10 & 2230 & 2.40 & 100 & 15 & 11 & 9 & 7.7 \\
\hline 17 Aug & 01:19 & 93.02 & 2363 & 1.06 & 25 & & 15 & 13 & 9 \\
\hline 17 Aug & $04: 14$ & 92.06 & 2443 & 2.21 & 115 & & 34 & 22 & 10 \\
\hline 17 Aug & 04:49 & 97.06 & 3317 & 4.70 & $\mathrm{NA}^{*}$ & & & 30 & 18 \\
\hline $22 \mathrm{Aug}$ & $23: 00$ & 96.48 & 2605 & 1.44 & 15 & & & 4.0 & 2.9 \\
\hline $22 \mathrm{Aug}$ & $23: 20$ & 95.42 & 2426 & 1.54 & 15 & & 6.5 & 3.8 & 2.8 \\
\hline $22 \mathrm{Aug}$ & $23: 50$ & 95.42 & 2930 & 3.17 & 10 & & & 5.3 & 2.6 \\
\hline 23 Aug & 00:05 & 97.73 & 2319 & 1.92 & 10 & & & & 3.8 \\
\hline 23 Aug & $00: 15$ & 97.15 & 2323 & 2.78 & 10 & & & & 3.9 \\
\hline 25 Aug & $02: 23$ & 94.56 & 5692 & 3.36 & 145 & 31 & 22 & 16 & 10.8 \\
\hline 26 Aug & 05:03 & 91.10 & 4158 & 6.91 & $\mathrm{NA}^{*}$ & & 29 & 16 & 10 \\
\hline 27 Aug & $21: 54$ & 92.93 & 4425 & 5.66 & 360 & 33 & 24 & 18 & 11 \\
\hline 27 Aug & $23: 34$ & 101.09 & 1545 & 3.65 & 70 & 20 & 11 & 7 & 3.6 \\
\hline $28 \mathrm{Aug}$ & 21:05 & 93.79 & 4227 & 3.74 & $\mathrm{NA}^{*}$ & & 36 & 20 & 16 \\
\hline $28 \mathrm{Aug}$ & $23: 15$ & 102.14 & 300 & 2.88 & 65 & & & & 12 \\
\hline $21 \mathrm{Sep}$ & $22: 03$ & 99.46 & 1837 & 3.94 & 90 & 20 & 15 & 11 & 8 \\
\hline $23 \mathrm{Sep}$ & $21: 53$ & 100.70 & 492 & 1.73 & 15 & & & & 12 \\
\hline $26 \mathrm{Sep}$ & $23: 30$ & 95.71 & 2324 & 1.92 & 140 & & 24 & 20 & 13 \\
\hline $27 \mathrm{Sep}$ & $19: 10$ & 100.9 & 1051 & 3.65 & $\mathrm{NA}^{*}$ & & 33 & 19 & 15 \\
\hline $28 \mathrm{Sep}$ & 00:00 & 96.38 & 2949 & 2.21 & 215 & & 48 & 19 & 14 \\
\hline
\end{tabular}

* NA, not available

by a common source process. The second is that the ionized Es layer is formed first by a wind-shear or electric field mechanism and that the neutral $\mathrm{Na}_{\mathrm{s}}$ layer forms afterwards by recombination of the sodium ions (Kirkwood and Collis, 1989; von Zahn and Hansen, 1988). On the basis of the timescales involved, von Zahn and Hansen (1988) rejected the latter mechanism. We noted that $\mathrm{Na}_{\mathrm{s}}$ layer events were generally characterized by corresponding increases in both ion and sodium column content (Beatty et al., 1989; Gerding et al., 2001; Mathews et al., 1993; Yi et al., 2013). These observed synchronous changes of the amounts of atomic $\mathrm{Na}$ and electron/ion obviously raise doubts about the latter suggestion, for this mechanism requires an inverse change between the amounts of ions/electrons and corresponding atoms. Simultaneous and common-volume three-lidar observations of sporadic metal layers indicate that the sporadic metal layers are usually a mixture of multiple metal atom and ion species, and that the density enhancements of all the sporadic metal atom and ion species occur in an overlapping altitude range and move following almost the same track, suggesting that all these metal species in a mixture are a product of the same or similar source processes (Yi et al., 2013). That the occurrence of $\mathrm{Na}_{\mathrm{s}}$ and Es is far from being 1 to 1 could be related to the ionization probability of the evaporating constituents, which depends both on meteoroid velocity and each chemical element (Janches et al., 2009).

Coincidently, during the 1999 Leonid activity there existed a significant small-scale fine structure with three central maxima coincident at three different sites separated by thousands of kilometers (Singer et al., 2000). The observations clearly showed quasi-periodic variations of the meteor rate with temporal separations of individual maxima in the 6 to 9 min range, and this periodic variation was observed in various data sets, which suggests the existence of fine structures within the dust trails along the earth's path, or spatial variations in the meteoroid density along the earth's path through the trail/stream (Rendtel, 2001; Singer et al., 2000). It appears to be consistent with the large horizontal dimension of $\mathrm{Na}_{\mathrm{s}}$ layers (Batista et al., 1991; Gardner et al., 1991; Kane et al., 1991). Moreover, the dual-beam radar observations indicate that the apparently downward moving Es layer was not tilted (Hysell et al., 2004), which implies that the observed Es layers were formed in a large horizontal area simultaneously.

Due to the lack of direct observational evidence for the existence of the micro-meteor swarms only in the region of 
the sporadic Na layers, the conjecture of direct deposition of large swarms of micrometeoroids with similar characteristics is difficult to be accepted at present. On the other hand, massive meteor trails have been observed by various radars (Briczinski et al., 2009; Ceplecha et al., 1998; Dyrud et al., 2011; Janches et al., 2001; Sugar et al., 2010; Zeng and Yi, 2011; Zhou and Perillat, 1998). Furthermore, there is some experimental evidence for a correlation between $\mathrm{Na}_{\mathrm{s}}$ and Es layer occurrence and meteor rates (Batista et al., 1989; Dou et al., 2010; Hansen and von Zahn, 1990; Hoeffner and Friedman, 2005; Höffner and Friedman, 2004), combined with the similar quasi-periodic oscillation and spatially localized scattering regions in $\mathrm{Na}_{\mathrm{s}}$, Es and meteor trails, so that a possible role of meteor deposition in the formation of $\mathrm{Na}_{\mathrm{s}}$ layers should not be discarded. Sporadic sodium layers usually cover a height range of several kilometers and exhibit short-period oscillations, and single meteoroids (Clemesha et al., 1978) cannot explain these two characteristics. However, there has not been any report so far on the large amounts of micro-meteor trails possibly related to Ns layers, even when the lidar observation was carried out on an individual laser pulse basis (Gerding et al., 1999; Hoffner et al., 1999). There are several possible explanations. First, the workers did not consider this question. Secondly, the detection capability of the lidar was not enough to detect these micro-trails. In this respect it should be noted that the metallic atoms detected were potassium and calcium, and these two metallic atoms have far lower abundances than those of sodium and iron in the meteor ablation region. Alternatively, the duration of these trails might be too short, on the order of milliseconds, to be detected by a lidar with a relative low repetition rate (Briczinski et al., 2009; Dyrud et al., 2011; Pfrommer et al., 2009). Only those metallic atomic trails strong enough and lasting long enough relative to the lidar would be discerned easily. That the formation of the $\mathrm{Na}_{\mathrm{s}}$ layers was usually accompanied by a group of $\mathrm{Na}$ meteor trails (Xie and Yi, 2010) seems to be in favor of this explanation. Thus, the peak heights between these $1.5 \mathrm{~s}$ adjacent profiles often appears to be chaotic, while on the order of minutes the peak height and the peak density frequently exhibit a systematic variation. The steep increase in Ca column density just before the onset of the strong meteor trail activity (Gerding et al., 1999) implies that there must have been large amounts of atomic $\mathrm{Ca}$ injected in the metal layer, only not enough for the Ca lidar return to be identified as conventionally defined lidar-detected trails (Gerding et al., 1999; Hoffner et al., 1999; Kane and Gardner, 1993; von Zahn et al., 1999).

Following a method similar to Hoffner et al. (1999) and Zeng and Yi (2011), we investigated meteor trail events during this period of observation. The statistics of photon counts received at each altitude channel for $1.5 \mathrm{~s}$ period is assumed to be described by a Poisson process. The mean value profile for this Poisson distribution is calculated by taking an average of 200 consecutive raw photon count profiles $(5 \mathrm{~min}$ ). A "meteor level" $C_{k}$ in the altitude range of the normal metal

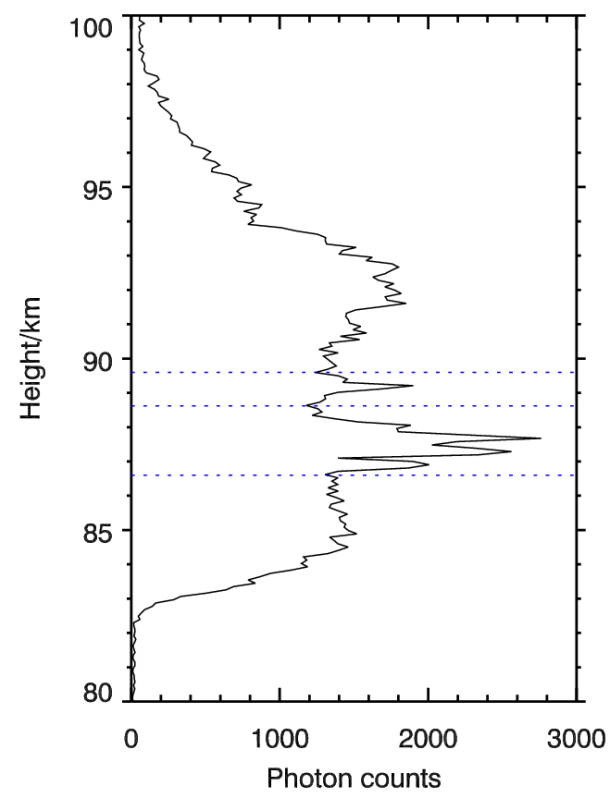

Fig. 10. The raw profile of a $\mathrm{Na}_{\mathrm{s}}$ layer with the integration time of $75 \mathrm{~s}$.

layers is defined with a statistical probability to reach $C_{k}$ being less than $10^{-8}$. At altitudes with negligible density of the normal metal layers, the meteor level is set to 7.5 photon counts (corresponding to a count rate of 0.3 counts $/ 96 \mathrm{~m}$ altitude channel and laser pulse). In terms of the calculated meteor level $C_{k}$, events with signal in altitude channel I larger than the corresponding value of $C_{k}$ are registered as potential trail events (PTEs). Then events that occur in adjacent channels are believed to arise from a single meteor trail. In the end, each "trail event" was affirmed by naked eye to exclude those false peaks. According to this criterion, the rate of trail detections was calculated to be 2.9 trails per hour during this period of observation. Next, we will show one typical example where $\mathrm{Na}_{\mathrm{S}}$ layers appeared to have consisted of meteor trails with longer durations. Although rare, this suggests that this scenario does occur.

\subsection{A typical example of meteor trails evolving into a $\mathrm{Na}_{\text {s }}$ layer}

During this campaign, we observed a typical example of meteor trails evolving into a $\mathrm{Na}_{\mathrm{s}}$ layer. Figure 10 shows the raw profile of this $\mathrm{Na}_{\mathrm{s}}$ layer, its duration is very short, not more than $1.5 \mathrm{~min}$, but it possesses almost all the characteristics of a $\mathrm{Na}_{\mathrm{S}}$ layer as usually observed. It was observed on 25 August 2010, between 21:51:28 and 21:52:43 LT, corresponding to a time resolution of $75 \mathrm{~s}$. Note that in the height range between 86.6 and $89.6 \mathrm{~km}$, there occurred two $\mathrm{Na}_{\mathrm{s}}$ layers, indicated between the blue dashed lines. One between 86.6 and $88.6 \mathrm{~km}$ with a full width of $\sim 2 \mathrm{~km}$, composed of multiple peaks, and the other between 88.6 and $89.6 \mathrm{~km}$ with a full width of $\sim 1 \mathrm{~km}$, composed of a single peak. 

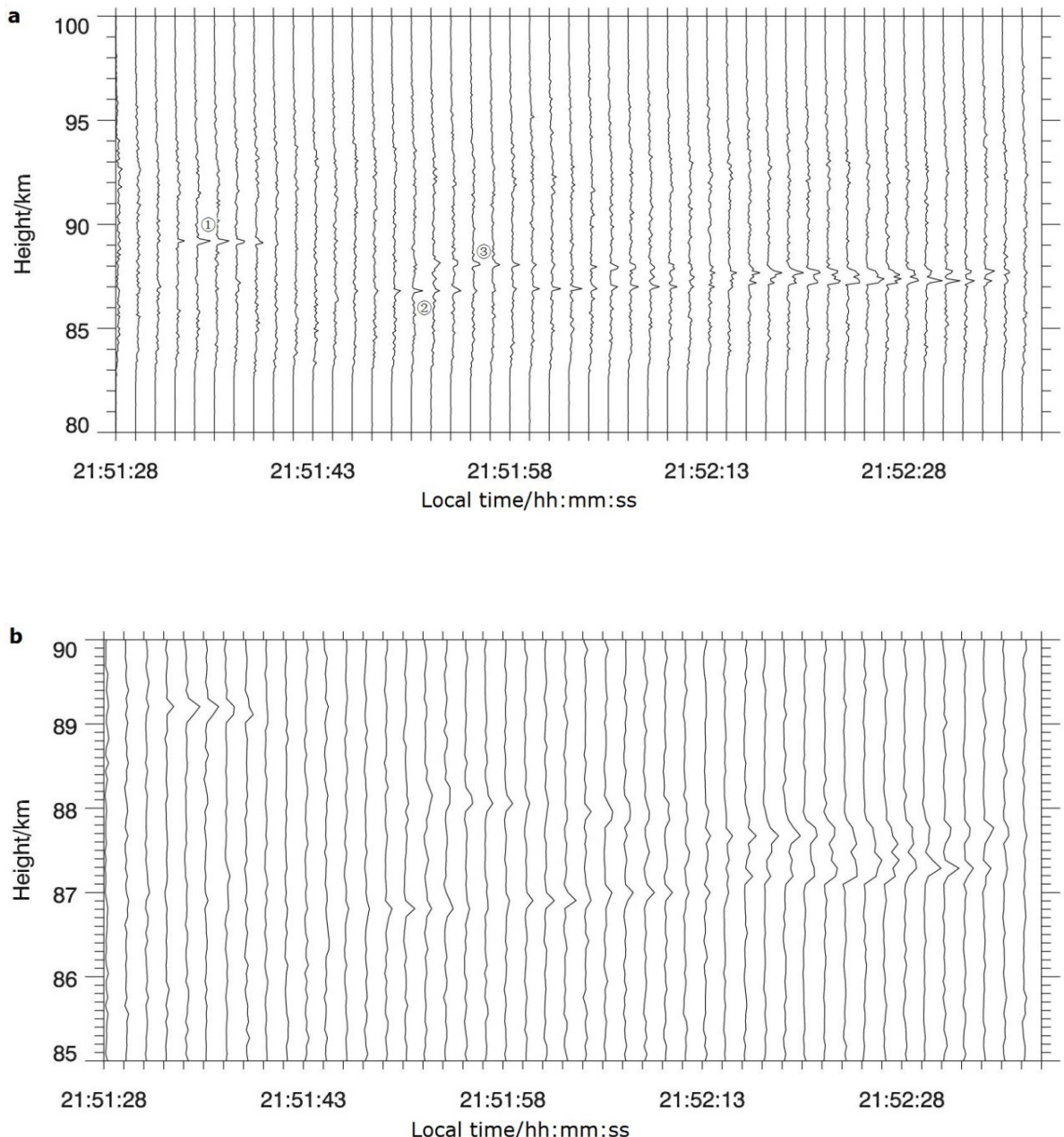

Fig. 11. (a) The evolution of the $\mathrm{Na}_{\mathrm{S}}$ layer in Fig. 10 observed at the time resolution of $1.5 \mathrm{~s}$ to show that each branch constituting the $\mathrm{Na}_{\mathrm{S}}$ layer, marked with (1), (2) and (3), corresponds to a meteor trail/multiple trails. (b) The same as (a) but on an expanded height scale, to show the similarity between this $\mathrm{Na}_{\mathrm{s}}$ layer and the conventionally observed $\mathrm{Na}_{\mathrm{s}}$ layers.

Figure 11a displays the whole evolution process of this $\mathrm{Na}_{\mathrm{s}}$ layer observed at the time resolution of $1.5 \mathrm{~s}$. Figure $11 \mathrm{~b}$ is the blowup of Fig. 11a on an expanded height scale. At first glance, there appeared three branches, indicated by (1), (2) and (3), respectively. Judged by the identification criteria proposed above, they are typical of meteor trails. The first, which corresponds to the $\mathrm{Na}_{\mathrm{s}}$ layer that occurred between 88.6 and $89.6 \mathrm{~km}$ in Fig. 10, began to form around $89.376 \mathrm{~km}$ at 21:51:32 LT, persisted for 5 consecutive profiles, and then disappeared at 21:51:40 LT. It went through a systematic increase and decrease process during such a short period. After about $4.5 \mathrm{~s}$ the second arose around $86.976 \mathrm{~km}$. It seemingly moved upward as a whole, with an apparent velocity of $12.9 \mathrm{~m} \mathrm{~s}^{-1}$, and it disappeared at $21: 52: 37 \mathrm{LT}$. About $6 \mathrm{~s}$ later after the second appeared, the third layer started around $88.320 \mathrm{~km}$. It moved downward apparently until 21:52:40 LT when it terminated, with the apparent velocity of $-10.5 \mathrm{~m} \mathrm{~s}^{-1}$. The second and third appeared like two coherent wave structures; they converged at 21:52:16 LT, and reached a maximum at 21:52:31 LT, when the two peaks were nearest and the structure was simplest. These characteristics were all observed by Clemesha et al. (2004), except that the timescale and vertical scale were different. Subsequently, the layers became more and more separated until they disappeared. We believe that this represents a minimal example of meteor trails evolving into a $\mathrm{Na}_{\mathrm{s}}$ layer.

Figure 12 illustrates the variations of the peak densities and the peak heights, corresponding to the first, the second and the third branches of Fig. 11 in turn. The red diamond indicates the peak density, and the blue triangle denotes the peak height. The vertical black bar represents the measurement error, and the horizontal black dashed line indicates the threshold chosen. Following the method of Gardner (1989), the relative measurement error of the $1.5 \mathrm{~s} \mathrm{Na}_{\mathrm{s}}$ peak density is calculated to be on the order of $\sim 8 \%$, thus the measurements on such a small timescale are reliable. Judging from 


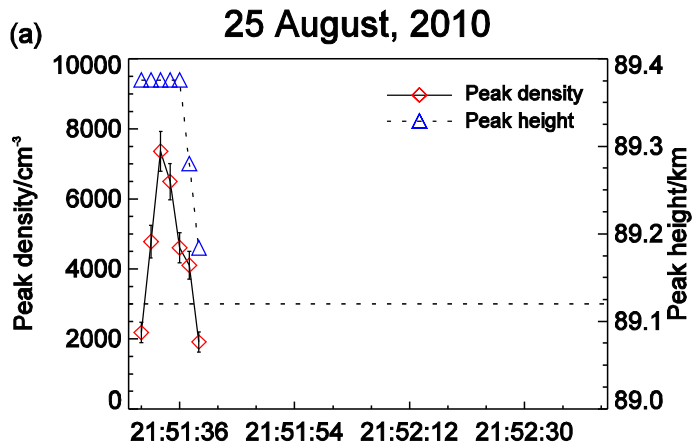

(b)

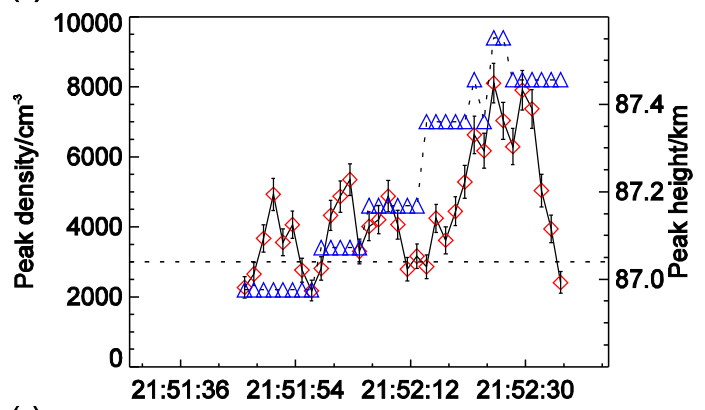

(c)

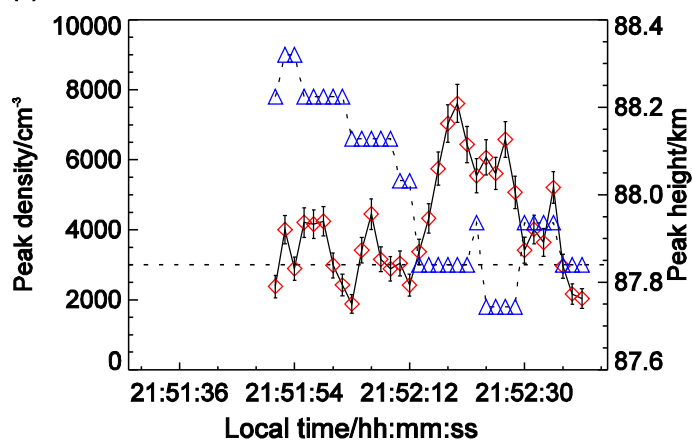

Fig. 12. The peak height and peak density variations of meteor trails corresponding to each branch of the $\mathrm{Na}_{\mathrm{s}}$ layer in Fig. 11 .

the variation of peak densities, this $\mathrm{Na}_{\mathrm{s}}$ layer consisted of a series of density enhancement bursts that occurred at different heights. The first lasts $7.5 \mathrm{~s}$ with a width of $\sim 288 \mathrm{~m}$ and peak concentration of $\sim 6010 \mathrm{~cm}^{-3}$. For the second branch, at least six bursts/trails could be identified easily, located at different heights. In general, the latter occurred at higher altitude than the former by one or two range bins, so this branch seemed to move upward. The third branch, similar to the second one, was made up of multiple bursts/trails, six of them being recognized easily. Unlike the second one, the latter occurred at one or two range bins lower than the former generally, so it appeared to be moving downward. For all the bursts/trails during this $\mathrm{Na}_{\mathrm{s}}$ layer, the intensities ranged from 1780 to $6970 \mathrm{~cm}^{-3}$ with the mean of $\sim 4360 \mathrm{~cm}^{-3}$. They last from 1.5 to $10.5 \mathrm{~s}$ with the average duration of $\sim 5.6 \mathrm{~s}$. Presumably, their durations are likely to be far shorter, limited by the time resolution adopted. The burst/trail widths varied from 96 to 288 meters, and some of them were not available because they were connected with each other in altitude. According to the classical meteoroid ablation theory (Love and Brownlee, 1991), all particles with the same size and density behave similarly, and the altitude at which peak heating (and thus the bulk of mass loss) occurs is similar for particles of all sizes, velocities, and entry angles, so these density bursts/trails that constitute this $\mathrm{Na}_{\mathrm{s}}$ layer probably resulted from meteoroids that have similar properties, which is consistent with the proposed formation mechanism of direct deposition of large swarms of multiple meteoroids with similar characteristics (Liu and Yi, 2009; Yi et al., 2008, 2013). Hitherto, we have demonstrated observations that multiple meteor trails evolve into a $\mathrm{Na}_{\mathrm{S}}$ layer, although it has been rarely observed until now. However, it must not be forgotten that the changes observed by the lidars are some combination of intrinsic temporal changes, and spatial variations along the direction of advection. The same goes for the observations of the ion layer. The observation that a strong ion layer coexists with a strong sporadic $\mathrm{Na}$ layer at a given point in time is not necessarily an argument against the ion-neutralization theory.

\section{Conclusions}

Based on the $1.5 \mathrm{~s}$ sodium lidar observations made at Yanqing, Beijing, China, we compare the $\mathrm{Na}_{\mathrm{s}}$ layer characteristics measured at different time resolutions. The result shows that individual $\mathrm{Na}_{\mathrm{s}}$ peaks are dispersed at different but adjacent heights, a fact which is concealed when observations are integrated over longer time intervals. We confirm the observations of Mathews et al. (1993), Pfrommer et al. (2009) and Tsuda et al. (2011) that there exist quasi-periodic oscillations on the order of several minutes in the peak height and peak density of $\mathrm{Na}_{\mathrm{s}}$ layers, which also appears to be a common phenomenon in Es layers and meteor rates. Furthermore, we found multiple discrete scattering regions in $\mathrm{Na}_{\mathrm{s}}$ layers as shown in Fig. 5b, frequently observed in Es layers (Hysell et al., 2004) and also in meteor trails (Mathews et al., 2010). These similarities support a strong link between $\mathrm{Na}_{\mathrm{s}}$ layers, Es layers and meteoroids. That the multiple thin layers with similar movement coincided locally suggests that the oscillations were not caused by atmospheric waves. Considering the extensive observations of the synchronous changes of metal atoms and ions/electrons, we question the suggestion that $\mathrm{Na}_{\mathrm{s}}$ layers are formed through the neutralization of Es layers and find it more probable that ionized Es layers and neutral $\mathrm{Na}_{\mathrm{s}}$ layers are formed by a common or similar source process: the direct ablation of large swarms of micrometeoroids as proposed by Liu and Yi (2009) and Yi et al. (2013). We also demonstrate as an observational fact that multiple meteor trails can evolve into a $\mathrm{Na}_{\mathrm{s}}$ layer. Although such a scenario is rare, it does demonstrate that this proposed formation mechanism can work. 
Acknowledgements. We are grateful to the Chinese Meridional Project for providing the sodium lidar data. We acknowledge financial support from the Fundaçao de Apoio a Pesquisa do Estado de Sao Paulo - FAPESP, and the National Natural Science Foundation of China through Grant 41104101.

Topical Editor C. Jacobi thanks three anonymous referees for their help in evaluating this paper.

\section{References}

Batista, P. P., Clemesha, B. R., Batista, I. S., and Simonich, D. M.: Characteristics of the Sporadic Sodium Layers Observed at $23^{\circ}$ S, J. Geophys. Res., 94, 15349-15358, 1989.

Batista, P. P., Clemesha, B. R., and Simonich, D. M.: Horizontal structure in sporadic sodium layers at $23^{\circ} \mathrm{S}$, Geophys. Res. Lett., 18, 1027-1030, 1991.

Beatty, T. J., Collins, R. L., Gardner, C. S., Hostetler, C. A., SechristJr., C. F., and Tepley, C. A.: Simultaneous radar and lidar observations of sporadic E and $\mathrm{Na}$ layers at Arecibo, Geophys. Res. Lett., 16, 1019-1022, 1989.

Briczinski, S. J., Mathews, J. D., and Meisel, D. D.: Statistical and fragmentation properties of the micrometeoroid flux observed at Arecibo, J. Geophys. Res.-Space, 114, A04311, doi:10.1029/2009JA014054, 2009.

Ceplecha, Z. V. E. K., Borovi, V. C., Ka, J. V. R. I., Elford, W. G., ReVelle, D. O., Hawkes, R. L., Porub, V. C., An, V. I. R., and Imek, M. V. S.: Meteor phenomena and bodies, Space Sci. Rev., 84, 327-471, 1998.

Clemesha, B. R.: Sporadic neutral metal layers in the mesosphere and lower thermosphere, J. Atmos. Terr. Phys., 57, 725-736, 1995.

Clemesha, B. R.: A review of recent MLT studies at low latitudes, Ann. Geophys., 22, 3261-3275, doi:10.5194/angeo-223261-2004, 2004.

Clemesha, B. R., Kirchhoff, V. W. J. H., Simonich, D. M., and Takahashi, H.: Evidence of an extraterrestrial source for the mesospheric sodium layer, Geophys. Res. Lett., 5, 873-876, 1978.

Clemesha, B. R., Batista, P. P., and Simonich, D. M.: Concerning the origin of enhanced sodium layers, Geophys. Res. Lett., 15, 1267-1270, 1988.

Clemesha, B. R., Batista, P. P., and Simonich, D. M.: Waveassociated sporadic neutral layers in the upper atmosphere, Revista Brasileira de Geofísica, 15, 237-250, 1997.

Clemesha, B. R., Batista, P. P., and Simonich, D. M.: An Evaluation of the Evidence for Ion Recombination as a Source of Sporadic Neutral Layers in the Lower Thermosphere, Adv. Space Res., 24, 547-556, 1999

Clemesha, B. R., Batista, P. P., Simonich, D. M., and Batista, I. S.: Sporadic structures in the atmospheric sodium layer, J. Geophys. Res., 109, D11306, doi:10.1029/2003JD004496, 2004.

Cox, R. M. and Plane, J. M. C.: An ion-molecule mechanism for the formation of neutral sporadic Na layers, J. Geophys. Res., 103, 6349-6359, 1998.

Cox, R. M., Plane, J. M. C., and Green, J. S. A.: A modeling investigation of sudden sodium layers, Geophys. Res. Lett., 2841-2844, 1993.
Dou, X. K., Xue, X. H., Li, T., Chen, T. D., Chen, C., and Qiu, S. C.: Possible relations between meteors, enhanced electron density layers, and sporadic sodium layers, J. Geophys. Res.-Space, 115, A06311, doi:10.1029/2009JA014575, 2010

Dyrud, L. P., Urbina, J., Fentzke, J. T., Hibbit, E., and Hinrichs, J.: Global variation of meteor trail plasma turbulence, Ann. Geophys., 29, 2277-2286, doi:10.5194/angeo-29-2277-2011, 2011.

Gardner, C. S.: Sodium Resonance Fluorescence Lidar Applications in Atmospheric Science and Astronomy, Proc. IEEE, 77, 408418, 1989.

Gardner, C. S., Kane, T. J., Hecht, J. H., Walterscheid, R. L., Yee, J. H., Niciejewski, R. J., Lowe, R. P., and Turnbull, D. N.: Formation Characteristics of Sporadic Na Layers Observed Simultaneously by Lidar and Airglow Instruments During ALOHA-90, Geophys. Res. Lett., 18, 1369-1372, 1991.

Gardner, C. S., Kane, T. J., Senft, D. C., Qian, J., and Papen, G. C.: Simultaneous Observations of Sporadic E, Na, Fe, and $\mathrm{Ca}+$ Layers at Urbana, Illinois: Three Case Studies, J. Geophys. Res., 98, 16865-16873, 1993.

Gerding, M., Alpers, M., Hoffner, J., and von Zahn, U.: Simultaneous $\mathrm{K}$ and $\mathrm{Ca}$ lidar observations during a meteor shower on March 6-7, 1997, at Kuhlungsborn, Germany, J. Geophys. Res.Space, 104, 24689-24698, 1999.

Gerding, M., Alpers, M., Höffner, J., and von Zahn, U.: Sporadic $\mathrm{Ca}$ and $\mathrm{Ca}^{+}$layers at mid-latitudes: Simultaneous observations and implications for their formation, Ann. Geophys., 19, 47-58, doi:10.5194/angeo-19-47-2001, 2001.

Hansen, G. and von Zahn, U.: Sudden sodium layers in polar latitudes, J. Atmos. Terr. Phys., 52, 585-608, 1990.

Höffner, J. and Friedman, J. S.: The mesospheric metal layer topside: a possible connection to meteoroids, Atmos. Chem. Phys., 4, 801-808, doi:10.5194/acp-4-801-2004, 2004.

Hoeffner, J. and Friedman, J. S.: The mesospheric metal layer topside: Examples of simultaneous metal observations, J. Atmos. Sol.-Terr. Phy., 67, 1226-1237, 2005.

Hoffner, J., von Zahn, U., McNeil, W. J., and Murad, E.: The 1996 Leonid shower as studied with a potassium lidar: Observations and inferred meteoroid sizes, J. Geophys. Res., 104, 2633-2643, 1999.

Hysell, D. L. and Burcham, J. D.: HF radar observations of quasiperiodic E layer echoes over North America, J. Geophys. Res.-Space, 104, 4361-4371, 1999.

Hysell, D. L., Yamamoto, M., and Fukao, S.: Imaging radar observations and theory of type I and type II quasi-periodic echoes, J. Geophys. Res.-Space, 107, 1360, doi:10.1029/2002JA009292, 2002.

Hysell, D. L., Larsen, M. F., and Zhou, Q. H.: Common volume coherent and incoherent scatter radar observations of mid-latitude sporadic E-layers and QP echoes, Ann. Geophys., 22, $3277-$ 3290, doi:10.5194/angeo-22-3277-2004, 2004.

Janches, D., Meisel, D. D., and Mathews, J. D.: Orbital properties of the Arecibo micrometeoroids at Earth interception, Icarus, 150, 206-218, 2001.

Janches, D., Palo, S. E., Lau, E. M., Avery, S. K., Avery, J. P., de la Pena, S., and Makarov, N. A.: Diurnal and seasonal variability of the meteoric flux at the South Pole measured with radars, Geophys. Res. Lett., 31, L20807, doi:10.1029/2004GL021104, 2004. 
Janches, D., Heinselman, C. J., Chau, J. L., Chandran, A., and Woodman, R.: Modeling the global micrometeor input function in the upper atmosphere observed by high power and large aperture radars, J. Geophys. Res.-Space, 111, A07317, doi:10.1029/2006JA011628, 2006.

Janches, D., Dyrud, L. P., Broadley, S. L., and Plane, J.: First observation of micrometeoroid differential ablation in the atmosphere, Geophys. Res. Lett., 36, L06101, doi:10.1029/2009GL037389, 2009.

Kane, T. J. and Gardner, C. S.: Lidar Observations of the Meteoric Deposition of Mesospheric Metals, Science, 259, 1297-1300, 1993.

Kane, T. J., Hostetler, C. A., and Gardner, C. S.: Horizontal and Vertical Structure of the Major Sporadic Sodium Layer Events Observed During ALOHA-90, Geophys. Res. Lett., 18, 13651368, 1991.

Kane, T. J., Gardner, C. S., Znou, Q., Mathews, J. D., and Tepley, C. A.: Lidar, radar and airglow observations of a prominent sporadic $\mathrm{Na}$ /sporadic E layer event at Arecibo during AIDA-89, J. Atmos. Terr. Phys., 55, 499-511, 1993.

Kirkwood, S. and Collis, P. N.: Gravity wave generation of simultaneous auroral sporadic-E layers and sudden neutral sodium layers, J. Atmos. Terr. Phys., 51, 259-269, 1989.

Liu, Y. and Yi, F.: Behavior of sporadic Na layers on small time scale, J. Atmos. Sol.-Terr. Phy., 71, 1374-1382, 2009.

Love, S. G. and Brownlee, D. E.: Heating and thermal transformation of micrometeoroids entering the Earth's atmosphere, Icarus, 89, 26-43, 1991.

Mathews, J. D.: Sporadic E: Current views and recent progress, J. Atmos. Sol.-Terr. Phy., 60, 413-435, 1998.

Mathews, J. D., Zhou, Q., Philbrick, C. R., Morton, Y. T., and Gardner, C. S.: Observations of ion and sodium layer coupled processes during AIDA, J. Atmos. Terr. Phys., 55, 487-498, 1993.

Mathews, J. D., Briczinski, S. J., Malhotra, A., and Cross, J.: Extensive meteoroid fragmentation in VUHF radar meteor observations at Arecibo Observatory, Geophys. Res. Lett., 37, L4103, doi:10.1029/2009GL041967, 2010.

Pfrommer, T., Hickson, P., and She, C. Y.: A large-aperture sodium fluorescence lidar with very high resolution for mesopause dynamics and adaptive optics studies, Geophys. Res. Lett., 36, 1-5, 2009.

Rendtel, J.: Periodic activity variations during the 1999 Leonid meteor storm in various data sets, edited by: Warmbein, B., Noordwijk, ESA Publications Division, Kiruna, Sweden, 2001.

Singer, W., Molau, S., Rendtel, J., Asher, D. J., Mitchell, N. J., and von Zahn, U.: The 1999 Leonid meteor storm: verification of rapid activity variations by observations at three sites, Mon. Not. R. Astron. Soc., 318, L25-L29, 2000.

Sugar, G., Oppenheim, M. M., Bass, E., and Chau, J. L.: Nonspecular meteor trail altitude distributions and durations observed by a $50 \mathrm{MHz}$ high-power radar, J. Geophys. Res.-Space, 115, A12334, doi:10.1029/2010JA015705, 2010.
Tsuda, T. T., Nozawa, S., Kawahara, T. D., Kawabata, T., Saito, N., Wada, S., Hall, C. M., Oyama, S., Ogawa, Y., Suzuki, S., Ogawa, T., Takahashi, T., Fujiwara, H., Fujii, R., Matuura, N., and Brekke, A.: Fine structure of sporadic sodium layer observed with a sodium lidar at Troms? Norway, Geophys. Res. Lett., 38, L18102, doi:10.1029/2011GL048685, 2011.

von Zahn, U., Gerding, M., Hoffner, J., McNeil, W. J., and Murad, E.: Iron, calcium, and potassium atom densities in the trails of Leonids and other meteors: Strong evidence for differential ablation, Meteorit. Planet. Sci., 34, 1017-1027, 1999.

von Zahn, U. and Hansen, T. L.: Sudden neutral sodium layers: a strong link to sporadic E layers, J. Atmos. Terr. Phys., 50, 93104, 1988.

von Zahn, U. and Murad, E.: $\mathrm{NaHCO}_{3}$ : a source of $\mathrm{Na}$ atoms for sudden sodium layers, Geophys. Res. Lett., 17, 147-150, 1990.

von Zahn, U., Von Der Gathen, P., and Hansen, G.: Forced release of sodium from upper atmosphere dust particles, Geophys. Res. Lett., 14, 76-79, 1987.

von Zahn, U., Goldberg, R. A., Stegman, J., and Witt, G.: Doublepeaked sodium layers at high latitudes, Planet. Space Sci., 37, 657-667, 1989.

Whitehead, J. D.: Recent work on mid-latitude and equatorial sporadic-E, J. Atmos. Terr. Phys., 51, 401-424, 1989.

Xie, Q. and Yi, F.: Preliminary lidar observations of Na meteor trails at Wuhan $\left(30.5^{\circ} \mathrm{N}, 114.4^{\circ} \mathrm{E}\right)$, China, Chinese Sci. Bull., 55, 2422-2427, 2010.

Yi, F., Zhang, S. D., Yu, C. M., He, Y. J., Yue, X. C., Huang, C. M., and Zhou, J.: Simultaneous observations of sporadic Fe and Na layers by two closely colocated resonance fluorescence lidars at Wuhan (30.5 degrees N, 114.4 degrees E), China, J. Geophys. Res., 112, D04303, doi:10.1029/2006JD007413, 2007.

Yi, F., Zhang, S., Yue, X., He, Y., Yu, C., Huang, C., and Li, W.: Some ubiquitous features of the mesospheric $\mathrm{Fe}$ and $\mathrm{Na}$ layer borders from simultaneous and common-volume $\mathrm{Fe}$ and Na lidar observations, J. Geophys. Res.-Space, 113, A04S91, doi:10.1029/2007JA012632, 2008.

Yi, F., Zhang, S., Yu, C., Zhang, Y., He, Y., Liu, F., Huang, K., Huang, C., and Tan, Y.: Simultaneous and commonvolume three-lidar observations of sporadic metal layers in the mesopause region, J. Atmos. Sol.-Terr. Phy., 102, 172-184, 2013.

Zeng, L. and Yi, F.: Lidar observations of $\mathrm{Fe}$ and $\mathrm{Na}$ meteor trails with high temporal resolution, J. Atmos. Sol.-Terr. Phy., 73, 2367-2372, 2011.

Zhou, Q. H. and Mathews, J. D.: Generation of sporadic sodium layers via turbulent heating of the atmosphere?, J. Atmos. Terr. Phys., 57, 1309-1319, 1995.

Zhou, Q. H. and Perillat, P.: Simultaneous meteor echo observations by large-aperture VHF and UHF radars, Radio Sci., 33, 16411654, 1998.

Zhou, Q. H., Mathews, J. D., and Tepley, C. A.: A proposed temperature dependent mechanism for the formation of sporadic sodium layers, J. Atmos. Terr. Phys., 55, 513-521, 1993. 